\title{
The Moderators of Post Purchase Regret
}

\author{
Melika Ben M'Barek and Abderrazak Gharbi
}

Faculty of Economic Sciences and Management of Tunis, Tunisia

\begin{abstract}
The objective of this research consists in exploring the factors influencing the regret experience.
\end{abstract}

To answer this objective, two techniques of data collection were used: the in-depth interviews and the focus groups.

The results of this research that allowed deduction of the factors involved in order to moderate the experience of regret are of situational order and individual order.

Keywords: Regret - situational moderators -counterfactual- individuals' moderatorssatisfaction.

\section{Introduction}

"One cannot live without desire, we cannot live without feelings and one cannot live without regret" (He, 2002). Who amongst us has never regretted a decision and ever said, "I have seen no other choice before buying! "'" I had to wait for Sales! "," I should have better negotiated my starting salary", "I should not have declared my love! » (Delacroix, 2003). Regret is everywhere in our lives and very few people are spared from the feeling of regret, and it's paid dearly. Regret is an important emotion; of course, it can intervene in all spheres of any person's life. That is why it has been the subject of a lot of research in various disciplines.

\section{Literature Review}

\section{Definitions of Regret}

Landman (1993) defines regret as "an emotional state that is more or less painful which is to feel sorry for misfortunes, limitations, losses, transgressions, shortcomings, and mistakes." If the comparison between the selected alternative and the rejected one is negative, the individual will regret but if this comparison is positive he will enjoy. Recently, Zeelenberg and Pieters (2006), Zeelenberg and Pieters (2007) and Lee and Cotte (2009) have reviewed the traditional definition of regret as a painful feeling that comes after the comparison of "... what it is..." and "... what could have been ... "(Sugden, 1985). They note that regret is felt when the result is unfavorably compared to a better result that could have been if it had been chosen differently (real or imagined) (Bell, 1982; Tsiros and Mittal, 2000 etc. ...), which is a one component of the concept of "regret." This component is known as "regret of result" (Zeelenberg and Pieters, 2006; Lee and Cotte, 2009). Recent research on regret assume that, regardless of the result, the quality of decision making used in the selection may be also regretted (Connolly et al, 2006). Regret of process is felt when the individual compares unfavorably the decision making process used in relation to another decision-making process that could have been used (Lee and Cotte, 2009).

"The regret can be felt because of process of decision (regret of process) or the

Copyright (c) 2011 Melika Ben M'Barek and Abderrazak Gharbi. This is an open access article distributed under the Creative Commons Attribution License unported 3.0, which permits unrestricted use, distribution, and reproduction in any medium, provided that original work is properly cited. Contact author: Melika Ben M'Barek E-mail: melikabm@gmail.com 
results of decision (regret of result)" (Zeelenberg and Pieters, 2007). The intensity of regret in the context of consumption may increase depending on the characteristics of the situation and personality (Delacroix, 2003). In this article, the researchers aim to present the contribution of previous research on regret moderators, and enrich this literature review on regret moderators with an exploratory study.

\section{The Regret Moderators}

According to Tsiros and Mittal (2000), there are several factors related to the situation, but also related to the personality that can increase the feeling of regret as well as the generation of counterfactual thoughts.

\section{The Situational Moderators}

Some characteristics of the situation increase the generating of mental simulations to compare between the reality and its alternatives. The key situational factors that influence the emergence and intensity of post-purchase regret reported in the literature review are: valence, perceived responsibility, the justifiability of the decision, the reversibility of the decision, the timing of the decision and the number of alternatives.

\section{a. The Valence}

The valence is often linked to the notion of pleasure-displeasure. Starting from the idea that the performance and noncompliance with expectations influence satisfaction (Anderson and Sullivan, 1993; Yi, 1990), the individual may be faced with two situations when assessing post decision-making: a negative or positive valence. Tsiros and Mittal (2000) have shown that people who buy a product whose performance is good rarely imagine alternatives to reality. However, when the consumer buys a product whose performance is unsatisfactory, he will have a greater tendency to generate counterfactual thoughts. In the same context, Zeelenberg and Pieters (2004) have shown that regret comes more from poor decisions and non-compliance with expectations.

\section{b. Perceived Responsibility: The Amount of Effort Invested in the Decision}

Regret is unique in its relationship with decision-making and here lies the responsibility (Zeelenberg and Pieters, 2007). Sugden (1985) concluded that the intensity of regret is often influenced by the level of individual responsibility and selfblame. Self-blame and responsibility proved to be a major component of regret. When individuals perceive that their decisions were unreasonable and inexplicable, they tend to feel responsible for having made the wrong decision (Van Dijk et al, 1999). However, Connolly et al. (1997) posit that responsibility is not a main component of regret. And it is through the work of Zeelenberg et al. (1998.2000) and those of Connolly et al. (2000) that these debates about the relationship between regret and responsibility have resulted in a consensus to decide that responsibility is an essential condition for triggering regret, but the decision is not mandatory. Other researchers have introduced the notion of effort amount invested in the decisionmaking rather than perceived responsibility. Thus, the more a consumer makes effort in decision making, the less he feels responsible in case of failure (Van Dijk et al, 1999).

\section{c. The Justifiability of the Decision}

Previous researches show that the decisions leading to a change of the status quo tend to get stronger emotional and cognitive responses than the decisions to maintain the status quo (Kahneman, 1995; Kahneman and Tversky, 1982; Landman 1987). The decision to change the status quo is often accompanied by a higher level of perceived responsibility, and therefore generates more regret in case of failure than the decision to maintain the status quo.Connolly and Zeelenberg (2002) criticize the contributions of previous research to the relationship between keeping or changing the status quo and regret, considering that this relationship 
depends on the context of decisions and experiences; a thing that was not mentioned in previous research. Thus, they have introduced the concept of justifiability of the decision to understand the phenomenon of status quo. They show that regret is minimized with the most reasonable and justified choices. On this basis, they developed the theory of decision justifiability that the feeling of regret comes from a combination of result assessment and the feeling of having made a non- justified bad choice.

\section{d. The Reversibility of the Decision}

The level of regret experienced, regardless of being actual or anticipated, can also be influenced by "the reversibility of the result." A result can dramatically reverse moderate level of regret experienced. Indeed, previous research has shown that irreversible alternatives can generate more regret than reversible ones (Engel et al, 1995; Landman, 1993; Tsiros and Mittal, 2000). For example, most consumers tend to regret their decisions in the absence of a guarantee in case of purchase with guarantee (Tsiros and Mittal, 2000). The irreversibility stimulates counterfactual thoughts which increase the feeling of regret (Mc Connell et al., 2000). With reversible alternatives, consumers are more passive, which makes them less likely to expend energy in cognitive counterfactual thoughts.

\section{e. The Timing of the Decision-Making}

Very few studies have focused on studying the impact of this factor on the intensity of post-purchase regret. This research shows that consumers tend to regret their purchase when they perceive that the same product purchased is offered in best opportunities later. If the consumer decides to wait for the best time to act, there would be a possibility of regret if the lost opportunity was more interesting than expected (Simonson, 1992). Specifically, consumers tend to feel more regretful and more upset if they expect a future sales opportunity and find later that they missed a better opportunity in the next period if they buy the alternative already available, and then discover they have missed a better opportunity to sell (Simonson, 1992). This has been attributed by Simonson to the fact that consumers expect to feel more responsibility if they expect a future sales opportunity and find later that they missed a better opportunity the next time they buy, because they were not able to predict what will happen in the future.

\section{f. The Number of Alternatives}

The moderating effect of the number of alternatives on market on regret is little explored by the literature review. The work in psychology and economics have shown that the high number of alternatives on market is advantageous because it allows people to match their personal preferences with the best options (Botti and Iyengar,2004). Schwartz (2000) pinpoints that the diversity and variety of choices (options) has several negative effects on well-being since it is incapable of organizing consumers' preferences and the only way not to feel regret is to choose the best option.

\section{Dispositional Moderators}

Is it possible that personality characteristics may be involved in causing the decision maker to feel more or less regret? The answer is a definite yes, and it's obvious that there is a systematic difference between people and their tendencies to regret (Schwartz et al, 2002). The main dispositional moderators of postpurchase regret cited in previous research are self-esteem, willingness to social comparison, temporal orientation, optimism vs. pessimism, "maximizing vs. satisfying", the risk aversion and rumination.

\section{a. Self-Esteem}

Self-esteem can be defined as a positive or negative attitude towards oneself. It is how the individual thinks of oneself in general (Mehrabian, 1998, 2000). Zeelenberg and Pieters (2004) revealed it is expected that the feeling of regret is strongly correlated with the level of self-esteem. This is consistent with the contribution of other 
previous works, namely those of Josephs et al. (1992) and Roese and Olsen (1993), who reported that individuals with low self-esteem are more motivated to protect their self-esteem when they take decisions.

\section{b. Social Comparison Disposition}

Gibbons and Buunk (1999), among others, have shown that some people have a greater propensity than others to compare themselves to others. Zeelenberg and Pieters (2002) argue that people who have a strong tendency to compare themselves to others regret their decisions more intensely than those without this pattern.

\section{c. The Temporal Orientation}

Boninger et al. (1994) demonstrate the moderating effect of temporal orientation. They elucidate that if the chosen option is evaluated less favorably than the rejected one, the forward-looking individuals experience less regret than people looking to the past. This is explained by the fact that people turned to see no possibility to improve in the future. Indeed, it was shown that individuals oriented toward the past tend to dwell on their experiences, while those oriented to the future use them as lessons to improve their future experiences (Markman et al., 1993; Böninger et al., 1994). For individuals facing future, negative experiences allow them to plan and improve future activities. While those who are oriented towards the past fail to do so (Taylor et al, 1989).

\section{d. Optimism and Pessimism}

Pessimists (those who interpret things negatively) tend to regret their choices more than optimists (those who interpret things in a positive way). Indeed, following an event, people who are optimistic pay more attention to the positive features of the situation than the negative characteristics (Miller and McFarland, 1994). Optimists reconstruct positively the performance after an event. Sanna (1996, 1998) studies this relationship between "optimism vs. pessimism" and regret through exploiting the impact of "optimism vs. pessimism" on engaging counterfactual thinking. Sanna showed that pessimists engage more in counterfactual thoughts in response to a negative experience than optimists who are committed to building more downward counterfactuals.

\section{e. "Maximizing vs. Satisficing"}

Schwartz et al. (2002) are among the first to study the behavior of "Maximizers" and "satisficers." They define a "maximizer" (maximizing) as a person who seeks the best in all his decisions and seeks to examine all available options. However, the "satisficer" is any person who accepts any option that can meet the selection criteria but not the best. People who are highly sensitive to regret tend to be "maximizer" (Schwartz et al, 2002). Schwartz et al. (2002) and Nenkov et al. (2008) point out that the trend towards maximizing converges to the tendency to feel more regret. This relationship should be better explored in this article.

\section{f. Risk Aversion}

The relationship between regret and risk is conditioned by the nature of information received after the decision (feedback). Zeelenberg et al. (2007) found that when consumers have to choose between a secure and risky gambling, those who expect a feedback on the secure option tend to choose the most secure option (safe); but those who expect to receive feedback on the risky option will choose it. According to Joseph et al. (1992), the choices that are not risky are the choices that minimize the potential regret. Zeelenberg et al. (1996) show that regret promotes risk aversion. similarily Mellers et al. (1999) assumed that as we tend to minimize the potential for regret, anticipation of regret is to hamper the taking of risk.

\section{g. Rumination}

The notion of rumination refers to helplessly thinking about something repeatedly (Debenedetti and Gomez, 2006). The relationship between regret and rumination was explained by referring to counterfactual thoughts. As long as the 
counterfactual thoughts involve people thinking in retrospect about past events, so those who tend to dwell on the past (ruminants) are more likely than others to generate counterfactual thoughts (Davis, 1991).

\section{Methodology}

To explore the regret moderators, the researchers have chosen a qualitative approach using two marketing qualitative methods of collecting data, i.e. individual qualitative interviews and focus group. Several methods of asking questions either projective or direct via the scenario technique, free association, the analog method, completing sentences and stories technique were used. And an interview guide was developed. The recruitment of participants and moderation of groups were conducted in a professional manner with a market research firm with audiovisual recordings, a two way mirror, etc. Our sample consists of 15 individual interviews: men and women, young and old from different social classes and different socio-professional categories. The researchers conducted four focus groups whose criteria were:

- Men or women.

- Age between 20 and 34 years and between 35 and 45 years.

- Social class: middle-lower classes and middle- higher classes.

\section{Results and Discussions}

Speeches made by respondents were fully transcribed by two expert transcribers. After completing the categorization and construction of analysis grids using the Nvivo 8, the researchers conducted a thematic analysis of the entire corpus: transcripts of interviews and focus groups.

\section{The Regret Moderators}

\section{A. Situational Moderators of Regret}

- Responsibility: more than $97 \%$ of respondents said, implicitly or explicitly, that the perceived responsibility or justifiability of the decision is an important stimulant of post-purchase regret feeling. Specifically, the more people see themselves responsible for bad choices and the more they perceive that they have not invested their effort in decision making, the more they tend to regret their choices more than others. Not defining its needs, not exerting sufficient and necessary effort in searching for information, not making a rational assessment and rigorous alternatives etc ... intensifies the feeling of regret for the consumer. Therefore, unjustified decisions tend to be regretted more than justified decisions. These results converge to those of Van Dijk et al. (1999); Bell (1985); Medevec Gilovich (1995); Sugden (1985); Simonson (1992); and Zeelenberg et al. (2000). It was already proved that among the defensive responses to cope with negative emotions, individuals throw responsibility for decisions on others. This defense mechanism is called "buck passing" (Anderson, 2003).

- The Valence: As demonstrated by Tsiros and Mittal (2000), people tend to regret more in case of discrepancy between expectations and product performance. This result appears frequently in the corpus overall answers like: "... it may be regretted as it was discovered that the existing options are not consistent with what he wanted ... "The majority of respondents say that the gap between the performance obtained and those expected of a product, or talking about their experiences real or fictional presented during the data collection is sufficient to increase the intensity of the feeling of regret or even generate it. In other words, the more the individual is dissatisfied with the purchased product (its quality, durability, price, value for money ...), the more it does not meet expectations and needs; and ultimately the more performance differs from the promises, the more the individual tends to regret his choice. The results of this work converge with the literature (Isen and Geva, 1987; Tsiros and Mittal, 2000). 
- The Choice between Brand Name and Price: Although previous research has not explored thoroughly the effect of the choice between brand name and price on regret, this relationship is important, because the respondents mentioned it many times implicitly or explicitly in their speeches. The opinions are not quite convergent as long as the majority says that the more the brand is known, the higher its price, the more quality and the less they tend to regret it "... besides I like quality brand products, I have never regretted ... ". Thus, the majority of respondents show a negative relationship between the choice between brand name and price and regret. Where to choose a known brand with an expensive price is a way to minimize the generation of post-purchase regret feeling. However, for others, although a minority, this relationship between brand name, price and regret is positive in so far as choosing a brand known for high prices stimulate the generation and increase the feeling of regret, especially after a negative experience. People can feel more regret when they buy the best known and most expensive brand, and find out later that it is not better in any way. These results converge with those of Simonson (1992) which show that there is a two-way relationship between regret and choice between brand name and price. Simonson (1992) suggested that in the context of choice between brand name and price, the relationship between regret and responsibility can have two directions. Consumers prefer the high price known brand to avoid the situation of regret. This is explained by the fact that they feel more responsibility when they buy the less known and expensive brand, and then see that it is less durable and less secure. Consumers complain more if they buy the best known and most expensive brand, and find out later that it is not better in any way. Also, those who choose brands that are not known and pay little, expect a poor quality and sometimes noncompliant with their expectations, and therefore they will not feel upset or regretful.
- The Justifiability of the Decision: the Status Quo: The notion of status quo or justifiability of decisions (Inman and Zeelenberg, 2002) has an effect on increasing the intensity of regret. This article has reiterated that individuals are more likely to regret the decision unjustified they see themselves more accountable for failure than decisions justified. Thus, they tend to change the status quo after a negative experience and maintain it after a positive experience. Remaining loyal to a brand with a positive experience is a way to minimize the error in the choice and subsequently the regret associated with it. "... As usual I have seen several offers and then I decided to buy from someone I know, as a matter of trust ... "Some interviewees perceive as abnormal, irrational and illogical behavior to change products with which one is satisfied. After a negative experience and when the change is not justified, the perceived responsibility of failure is high and therefore the probability to regret the choice rises. Thus, the relationship between regret and status quo is significantly positive in the absence of logical reasons for change and vice versa.

- Nature of Purchase: Analysis of openended questions with objectives to explore the situational moderators of regret deduces that the nature of the purchase has an effect on the increase even on the generation of post-purchase regret. Interviewees tend to regret more impulsive buying rather than planned purchase. Thus, the respondents see themselves more responsible for the error when it comes to an impulsive purchase, because the planned purchase involves investing the effort required in each step of the buying process and reversing impulsive buying when it goes directly to action. When it comes to an impulsive buying, it is more the emotional side that will respond. And thus no forecast is made in advance and the emotional side stimulates the buying action. Thus, respondents see themselves more responsible for the error if it is an impulsive buying, and they tend to regret 
more. This factor was not mentioned in any previous research to our knowledge.

- The Timing of Decision Making: Almost $60 \%$ of respondents mentioned the importance of timing in their purchasing decisions and in the moderation of their post-purchase feelings. Buying a product and then perceiving that a better condition of sale was missed before or after the purchase is an important stimulus of post-purchase regret feeling. The more time allocated to decision making is close to the optimum time, the less likely is the choice regretted. Some respondents mentioned their regret was because of missing an opportunity: "... Those who expect lower prices as much as possible but ultimately find nothing, and sometimes they buy anything or they buy poor quality and therefore regret their purchases ... ". A missed opportunity is normally accompanied by a high degree of responsibility for not optimizing the time of purchase which leads to the generation of regret. One feels responsible due to not seizing the opportunity when available. It is the regret of inaction.

By converse implication, sense units indicating that after purchasing a product and realizing that the same is available in much better conditions (cheaper, with more options, with the same price and with additional accessories ...) are much more common, under such conditions two types of reasoning were discussed. Some respondents see themselves responsible for the error in the timing of decision making, since they did not foresee the possibility of buying the same product in the best opportunities later. Others completely rid themselves of this responsibility, the failure is beyond their control and they justify it by the fact that it was impossible to predict the optimal time of purchase or price reductions as they don't even have the profile to do. For these respondents, the degree of regret experienced is much lower than that experienced by the former. The present results converge with those of Simonson (1992).
- The Sale Service: Exploring regret moderators allowed concluding that the Sales Service has an important effect on the intensity of the feeling of postpurchase regret. Despite the clear importance of this factor in this qualitative research, it was not mentioned in the literature review. What was proven is that the more the consumer feels to be "ripped off" by the Service, the more he tends to dwell on the past, and thus the more he tends to regret his choice. The Service is reflected in the reaction of vendors, their involvement in decision making and even in the after sales service. The more information received from vendors are wrong; the more sales service is poor; and the advice given is not reliable, the more respondents will blame themselves for the failure. They then tend to regret their purchases but they also regret accepting to be submitted under the pressure of Sales Service. Verbatim such as "it is the vendor who pushed me to buy this product he misled me and he said it is fashionable and that we will no longer have this model and I will benefit $a$ discount" were received.

- Involvement: Detailed analysis of the sense units related to situational moderators of regret concludes that the level of involvement has an obvious effect on the moderation of regret. Specifically it was clear that people have less regret with regards to high degree involvement products than those with low level. They tend to regret expensive products rather than cheap products. Indeed, as demonstrated by few previous researches, involvement with the decision in question may have an important effect on enabling counterfactual generation (Meyers-Levy et Maheswaran, 1992), and situations with high degree of involvement can contribute to feelings of control over decision making(Desmeules, 2002) which leads to positive effect on postpurchase regret involvement.

- Reversibility: A decision is reversible if the result (or option) can be changed 
after purchase. This article points out like Zeelenberg et al (1996), Engel et al (1995), Landman (1993), Tsiros et Mittal (2000), Delacroix (2003) ... that irreversible decisions provide more regret than reversible ones. To minimize this feeling of regret when evaluating post-purchase, people tend to choose mostly reversible alternatives, with a warranty, for example because they are safer, "... Of course the warranty is important, at least it is a mark of safety and integrity of the brand ... "'" ... The warranty is a mark of safety that brings down regret ... ".In addition to reversible alternatives, consumers are more passive, which makes them less likely to expend cognitive energy in counterfactual thoughts.

- The Number of Alternatives: The sense units defined in this category are more or less redundant. The more choice is limited, the more failure is justified and the less regret is intense "after all ... I had no choice, I was obliged...." And the more choices there are, the more anticipated regret is restricted and the more postpurchase regret is intense. In other words, when the number of available alternatives is high, people feel happier because they are more than likely to choose carefully, but they feel more responsible and they have no room for error. For this reason, in case of failure they regret more. So, when there are several alternatives, task becomes very difficult and complicated. This increases the feeling of post- purchase regret, since commitment to comparative and counterfactual thinking will be easier "... in fact, I was torn between two options and finally I chose the second one, I should have chosen the first ... ". This is particularly experienced by "maximizers" or perfectionists who look for the best decision possible. The moderating effect of the number of alternatives on regret available on market is little explored by the literature review. The present finding concur with the result of some work in psychology and economics that revealed that the high number of alternatives on market is advantageous because it allows people to match their personal preferences with the best options (Botti et Iyengar, 2004), although the increase in the number of alternatives can make the choice less attractive, so much that some individuals delegate the choice to others (Beattie et al, 1994). Individuals facing a lot of options feel more responsible for their choices because they have the potential to find the best option. This implies a higher level of regret when they have not invested enough time and effort to find the best option. They regret more as they become unable to arrange their preferences in choosing (Schwartz, 2000).

\section{B. Dispositional Moderators of Regret}

In addition to the characteristics of the situation, the personality characteristics are also involved in the moderation of regret. It should be noted that these personality factors were much explored by the projective techniques used throughout the interviews and focus groups.

- Willingness to Social Comparison: An analysis of the sense units identified in this category points out that the disposition to social comparison is among the main factors that can increase or decrease the intensity of the feeling of regret at the post-purchase assessment. This result which is based on the theory of social comparison (Festinger, 1954) was provided in several other studies, namely those of Gibbons and Buunk (1999); Zeelenberg and Pieters (2002) and Delacroix (2003). The contribution of this paper is to understand the effect of the involvement of others before, during and after the purchase decision on the intensity of the post-purchase regret feeling. On several occasions, the respondents mentioned that being influenced by others prior to the decision-making such as purchasing a product similar to that owned by a friend, or to follow a trend, or just to show the belonging to a certain social class without being convinced, increases most certainly the feeling of postpurchase regret. "... So following others, buying what everyone else buys and ignoring one's own needs is not free, 
regret is the price you have to pay.That's $i t$ ! ... ".The involvement of others in the very act of buying is a two-way relationship with regret. On the one hand, and especially after a negative experience, those who make their final decisions under the influence of a third person will be more responsible for the discrepancy between their expectations and needs and the actual performance of the product. "... I should have seen more options and buy only the product that appeals to me, not the one appealing to someone else ...".

On the other hand, some respondents argue that significant comparison with others is a way to help oneself making the right choice; thus minimizing postpurchase regret. This is explained by the fact that they try to make the required effort in terms of choice, information research and evaluation of available alternatives and therefore minimizing the perception of responsibility in case of failure. "... I should have come with my friends because my friends can help and recommend to me the right choice ... ".After the purchase, respondents agree that individuals who tend to compare themselves to others are more likely to regret their choices than others. Also, individuals who are sensitive to other people's criticism and who agree to be judged by them are more likely to regret their choices than others. "... Under pressure of my brother's opinion who told me why did I buy this old-fashioned phone, with an amount that could allow me to buy another one more fashionable ... ".

- Impulsivity: The fact that the individual is impulsive in his/ her choices is likely to stimulate an obvious regret for almost all the interviewees. This work has proven for the first time that impulsivity is one of the major personality characteristics moderating the feeling of post-purchase regret. Thus, people who are impulsive tend to regret their choices more than non-impulsive people. This is due to the fact that impulsivity is often accompanied by not providing enough effort in decision making; therefore the perception of greater responsibility in case of failure in making the right decision.

- Temporal Orientation: An analysis of the sense units identified in this category attests the existence of a temporal orientation moderating effect on postdecision regret. As evidenced by Böninger et al (1994) and Delacroix (2003), temporal orientation has a significant moderating effect on the generation of regret among consumers in the evaluation of their decisions. Specifically, the majority of opinions agree on the fact that individuals who are oriented toward the past tend are to regret more than those who are oriented toward the future. Indeed, those who are oriented toward the past cannot forget it and cannot easily forget afterwards the past positive and mainly negative decisions. They tend to dwell on the past and engage in more counterfactual reasoning. Repeatedly, respondents said that they prefer to not to linger on the past in order to avoid regret "... But generally I do not like going back in time to compare because it affects me in the heart ...".

- Optimism vs. Pessimism: The researchers conclude that pessimists tend to regret more than optimists. "... We must just see the good side of things, not being too negative ... ". The interviewees believe that optimism helps in easily forgetting the negative experiences and thus minimizing their feeling of regret. Optimists undertake less comparative reasoning and evaluate more positively their decisions. Optimists have strong post purchase regret control strategies. The present findings converge with the previous work; in fact, it was demonstrated that pessimists tend to regret more than optimists. This is due to the fact that optimists are more likely to compare their situations to less favorable situations. On the other hand, pessimists compare their situations to more favorable situations (Kasimatis et Wells, 1995). Besides, pessimists cannot easily forget their past and especially the negative experiences and pay more 
attention to negative features than positive features of the situation (McFarland et Miller, 1994; Sanna, 1996, 1998).

- Perfectionism: This article reveals the importance of perfectionism in the moderation of post-purchase regret. Although this characteristic is not mentioned in any previous research, it is significant and deserves to be mentioned. What is mentioned is that the perfectionist i.e. those who are very demanding in terms of choice and expectations, tend to regret more than others. The analysis of the sense units related to perfectionism leads to the conclusion that such perfectionists' expectations are accurate and they are so demanding that it is not easy to find the choice that can fully satisfy them. Perfectionists are not easily satisfied by their decisions and engage in counterfactual thoughts. "... Perfectionists are people who regret more because their selection criteria are very complex, therefore, they will not be very likely satisfied with purchases ...".

- "Maximizing vs. Satisficing" This category was mentioned on several occasions by the respondents either explicitly or implicitly. The projective techniques used highlights that "maximizers" tend to engage in comparative reasoning more than others. However, those who seek only to reach a definite level of satisfaction are no more motivated by comparative reasoning. Once that level of satisfaction is guaranteed they feel happy and they move on to something else. So, the satisficers regret less than maximizers. Thus, the impact of the rejected option of post purchase evaluation is more intense among "maximizers" than "satisficers" as they reach their equilibrium when choosing the best option. The notion of "satisficing" was not well explored by the literature review and it deserves to be mentioned in this article because it was often mentioned in interviews conducted with individuals and groups. The present results converge with those of Schwartz et al (2002) who found that "maximizers" engage more in social comparisons and are more concerned with what others do. So, they generate more counterfactual thoughts. Thus, the rsearchers have proved that "Maximizers" regret more and feel less happy with their choices, they are less satisfied about their lives and feel less joy, optimism and selfesteem. Nenkov et al. (2008) writes "Potential regrets are often present as" maximizers "are always wondering whether the choice they made is the best and are always doubtful about it ." Note that "maximizers" tend to be perfectionists (knowing that psychologists say these two are separate).

- Risk Aversion: it is an important moderator of regret. When it was established that "risk tolerant" people, i.e. those who are innovative and "dare " to try a product or brand they do not know, are more likely to regret than the risk-averse. In fact, with low levels of risk people give less consideration to their choice and feel less responsible in case of failure. To minimize the probability of making a bad choice and not to regret, interviewees suggest not taking the risk and engaging in the ambiguities of an unknown brand or innovation "... Let the adventurers try and then you'll find yourself much more comfortable ... ".However, and less frequently mentioned, risk tolerant people regret less than risk averse ones because they are less sensitive to negative experiences and they are psychologically prepared to loss and gain "... life is a game and to win you should play and you lose when you play so you have to accept the loss ...." Thus, risk-averse people have stronger regret control strategies.

- Self-esteem: This personality characteristic is negatively related to post-purchase regret- the more the individual has self-confidence, the less he tends to regret his choice; while those with low self-esteem do not value their decisions and easily engage in counterfactual reasoning. Individuals with low self-esteem are more likely to negatively evaluate their decisions. They 
feel more responsible for failure. This result is accentuated by previous research especially that of Roese and Olson (1993) and Brown and Smart (1991).

- Hesitation: hesitation is supposed to have a positive connection with regret. The hesitating individual, who does not decide quickly and easily and lacks confidence and firmness, is more likely not to make the right choice, and thus is more likely to regret the decisions than non-hesitating people. When one hesitates one is not sure of one's choices, so one tends to engage more in comparative reasoning later. This factor was often mentioned by respondents although it was not mentioned in any previous work.

- The Age: comparative analysis of young vs. aged respondents' answer clearly points out that age has a very important moderating effect on the emergence and intensity of post purchase regret. The analysis of sense units identified in this context implies that the elderly tend to have less regret than young people because they have sufficient expertise to successfully make the right choice, though the young are less skilled and more impulsive which makes them regret more.

- Gender: corpus analysis allowed us to infer that females tend to regret more than males for various reasons. First, females are more sensitive and emotional than males so it is more likely to display emotional responses. Second, females tend to engage more in comparative reasoning which intensifies the emergence of regret. The portrait of the person who tends to regret more often has been a sensitive young female.

- Rumination: It was repeatedly referred to, implicitly or explicitly that ruminators talk repeatedly about their decisions and are not able to overcome their failures. They engage in comparative reasoning from negative experiences more than positive ones. The Profile of a ruminator is very close to the profile of one who often tend to feel regret, "a young woman with a strong tendency to persist in an action, a tendency to assume responsibility in case of failure, a rather low self-esteem, a tendency to regret her decision to be pessimistic and lie more in the reflection than in action, finally, she had difficulty in communication. " rumination is an important moderating factor of regret even if it is not reported in any works on regret.

\section{Synthesis and Interpretation}

The exploration of regretting consumer behavior has identified the main factors that can stimulate the generation of regret feeling and influence its intensity when assessing post purchase. As in Delacroix's research (2003), these factors are classified into two categories.

\section{A. Situational Moderators}

This category includes characteristics related to the situation, emerging from the overall corpus that promote among the surveyed population the generation of mental simulations to compare the reality and its alternatives. Although previous research has demonstrated that various situational characteristics may occur when evaluating post-purchase in order to moderate the intensity of regret feeling, several other situational factors mentioned in very few researches on regret or not at all mentioned are tackled in this article and deserve to be better explored in future research. Thematic analysis of data collected during the investigative stage of this empirical work has, on the one hand, allowed to prove again, like many other previous researches, that perceived responsibility; or the amount of effort invested in decision making, the valence and the status quo; or the justifiability and reversibility of decision have a significant effect in moderating the intensity of regret when evaluating post purchase. On the other hand, the results have generated other situational factors that were mentioned by very few previous researches or almost absent in the most recent researches that focused on exploring consumer's experience of regret. Interviewees often felt that the choice 
between brand name and price has a great effect in moderating the feeling of post purchase regret. This relationship between regret and the choice between brand name and price varies in both directions.

On the one hand, the majority of respondents said that choosing a brand name at a high price is a way to avoid the situation of regret. On the other hand, some respondents mentioned that when they choose a brand that is not known and not expensive, they will not regret. This is explained by the fact that when choosing a brand that is not known and with a low price, they expect a non-compliance with their expectations and they will not be regretful or upset if it does.

Although this category has frequently appeared in the overall corpus, only Simonson (1992) noted it in his research. Simonson (1992) is also the only one, as far as it is known, who proved that the choice of the decision making time has an effect on the intensity of the feeling of post purchase regret and even its making.

This article has also shown that the choice of decision making time is important in the purchase decision in post purchase evaluation to the extent that respondents have revealed their tendency to optimize the time of decision making to avoid the situation of regret. Further analysis of sense units on the situational moderators posit that consumers complain more about products with a high degree of involvement than those with low level of involvement. Very little research has suggested this positive effect on the degree of involvement in the post purchase regret (Meyers-Levy and Maheswaran, 1992; Desmeules, 2002). Very few researches also studied the relationship between the number of alternatives on market and regret. This category was widely mentioned in the answers of the respondents. Finally, data collected during the empirical investigation of this work have put forward two other situational factors that were not mentioned in the literature i.e. the Sales Service and the nature of purchase. Repeatedly, interviewees mentioned implicitly or explicitly that the Sale Service is a key factor that has a significant effect on the amplification of post purchase regret feeling and even contributing to its generation. What was demonstrated in this work is that the respondents perceive badly Sale Service; more precisely, the more they feel "ripped off" by vendors and after-sales service, for example, will not be performing well, the more they tend to regret their purchases.

Also, this article demonstrates that the Tunisian consumer tends to regret more impulsive than planned purchase. This is explained by the fact that people feel more responsible for failure if they buy impulsively, because they have not invested enough in decision making than when they buy in a planned manner.

\section{B. Dispositional Moderators}

Recently, Delacroix (2003) was interested in works that have focused on understanding the dispositional mechanisms and its impact on consumer's experience of regret. The qualitative research techniques and especially projective techniques have encouraged the exploration of these dispositional moderators in the context of consumption. The contribution of this present work tends to meet the same conclusions with that of previous work (discussed in the first part of this article) by demonstrating again that the characteristics related to personality, such as the disposition to social comparison, temporal orientation, optimism and pessimism and self-esteem affect the intensity of regret when evaluating post purchase.

However, other characteristics related to personality like impulsivity, perfectionism, risk aversion, the "maximizing vs. satisficing", hesitation, rumination, perfectionism, hesitation, gender and age must be taken into account to better understand the consumer's experience of regret .

Indeed, analysis of the sense units related to dispositional moderators shows that impulsivity has a positive effect on regret; 
that is, impulsive consumers tend to regret their choices more than non-impulsive consumers as they don't invest enough effort in making a decision they are more emotional than rational, and therefore they feel more responsible for the failure primarily due to a negative experience.

The respondents considered implicitly or explicitly that perfectionists, those who are very demanding in terms of choice, are more likely to regret their choices because they are often not in line with their expectations. Similarly, maximizers regret more than satisficers because they are more motivated to engage in comparative and counterfactual reasoning.

In this paper, the researchers show that risk aversion stimulates comparative reasoning in assessing post purchase. This leads risk-averse people to more likely regret their choice than risk tolerant people, as they consider themselves more responsible for the error due to a negative experience. The analysis also reveals that risk tolerant people regret less because they have a strong ability to accept failure. This discrepancy can be explained by the fact that risk-averse strategies have very strong regulation of regret and they are very able to overcome their failures.

Finally, a minority of respondents felt that more hesitant people tend to regret their choice than non hesitants because they are more likely to err in making the right decision; hence engage in more comparative reasoning in post purchase evaluation. Ruminators regret more than non-ruminants because they keep trotting out about the past and don't have a strong ability to overcome failure. Women tend to regret more than men and younger regret more than elders because the latter have acquired sufficient expertise in life to avoid mistakes in their choices, they engage less in comparative reasoning and are less impulsive and rarely feel responsible for any regret. Also, they have very strong control strategies over regret especially religious, "it is God's will ...".

Limitations and Future Directions of Research: Although the approach taken in this article sheds light on post-purchase behavior of consumers, some limitations and methodological questions deserve to be explored in future research.

- In this article, the moderators of regret were grouped into two categories moderators: situational and dispositional moderators. These two aspects were studied independently, as in almost all previous researches, but the interactions between personality and situation variables have not been studied with elucidation. This dichotomy refers to the debate between two paradigms: that of differentialists (Eysenck, 1967), who consider that behavior can be explained primarily by the personality and the Situationists (Mischel, 1968), for whom the characteristics of the situation are sufficient to explain behavior. The debate was resolved through the development of interactionist models (Bowers, 1973), interested in the interactions between personality and situations characteristics. It will shortly be relevant to study in future research these interactions as part of the experience of regret to determine how different types of people react to situations that can cause regret.

- We had to go to a confirmatory phase to test the new variables identified in this paper via a quantitative study. 
The Moderators of Regret

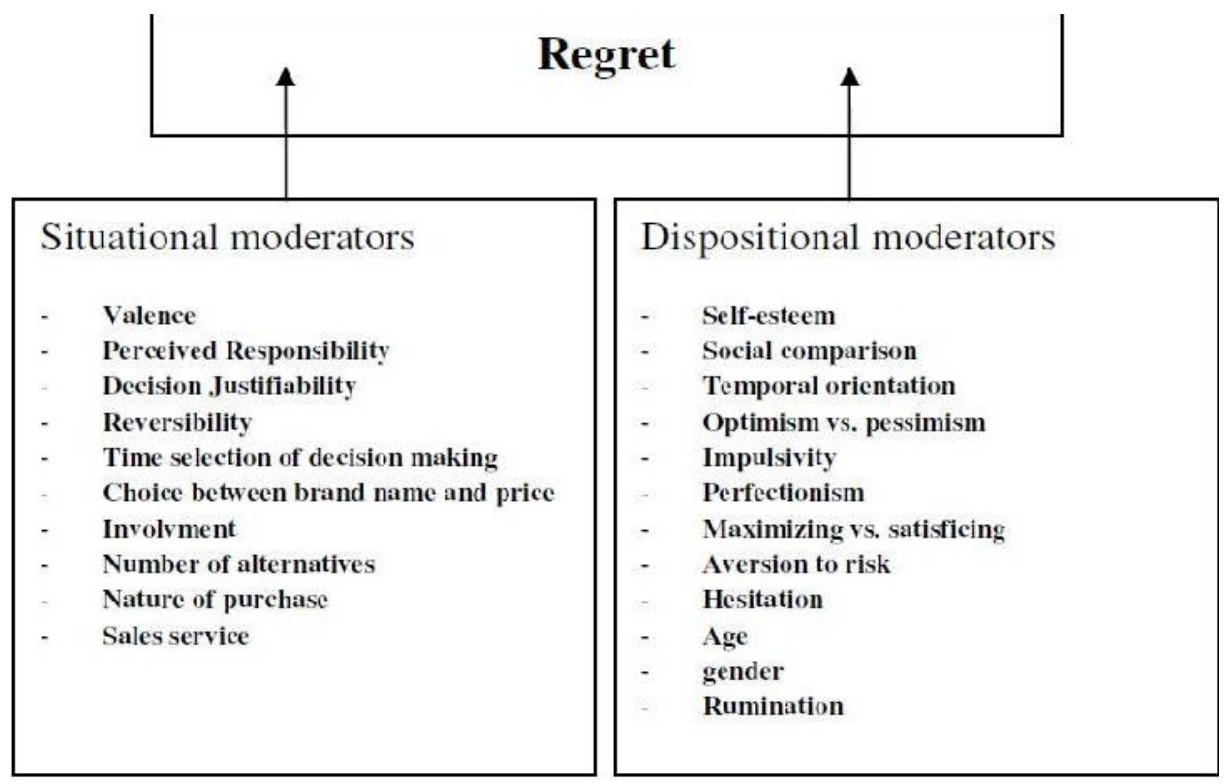

\section{References}

Anderson, E. W. \& Sullivan, M. W. (1993). "The Antecedents and Consequences of Customer Satisfaction for Firms," Marketing Science, Vol. 12, Pp. 125-143.

Anderson, J. C. (2003). "The Psychology of Doing No Thing: Forms of Decision Avoidance Result from Reason and Emotion," Psychological Bulletin, Vol. 129, $\mathrm{N}^{\circ} .1, \mathrm{Pp} .139-167$.

Beattie, J., Baron, J., Hershey, J. C. \& Spranca, M. D. (1994). "Psychological Determinants of Decision Attitude," Journal of Behavioral Decision Making, Vol. 7, Pp. 129-144.

Bell, D. E. (1982). "Regret in Decision Making Under Uncertainty," Operations Research, Vol. 30, Pp.961-981.

Bell, D. E. (1985). "Disappointment in Decision Under Uncertainty," Operations Research, Vol.33, (January- February), Pp.127.

Boninger, D. S., Gleicher, F. \& Strathman, A. (1994). "Counterfactual Thinking: from What Might Have Been to What May Be," Journal of Personality and Social Psychology, Vol. 67, Pp. 297-307.
Botti, S. \& Iyengar, S. S. (2004). "The Psychological Pleasure and Pain of Choosing: When People Prefer Choosing the Cost of Subsequent Outcome Satisfaction," Journal of Personality and Social Psychology, Vol. 87, N³,Pp. 312-326.

Brown, J. D. \& Smart, S. A. (1991). "The Self and Social Conduct: Linking SelfRepresentations to Prosocial Behavior," Journal of Personality and Social Psychology, Vol 60, N³, Pp. 368-375.

Connolly, T. \& Zeelenberg, M. (2002). "Regret in Decision Making," Psychological Science, Vol.11, Pp. 212-216.

Davis, S. (1991). Pragmatics, A Reade, (Ed.) Oxford University Press, 595 Pages.

Debenedetti, A. \& Gomez, P. (2006). "La Théorie De La Rumination: Etat De l'Art Et Perspectives De Recherche En Comportement Du Consommateur," Recherche et Application En Marketing, Vol. 21, No. 1, Pp. 41-55.

Delacroix, E. (2003). "Le Regret Chez Le Consommateur : Un Etat De L'art," Cahier De Recherche. 
Desmeules, R. (2002). "The Impact of Variety on Consumer Happiness: Marketing and the Tyranny of Freedom," Academy of Marketing Science Review, No.12, Pp. 1-18.

Engel, J. F., Blackwell, R. D. \& Miniard, P. W. (1995). 'Consumer Behavior,' Dryden, New York.

Gibbons, F. X. \& Buunk, B. P. (1999). "Individual Differences in Social Comparison: Development of a Scale of Social Comparison Orientation," Journal of Personality and Social Psychology, Vol.76, $\mathrm{N}^{\circ}$. 1, Pp. 129-142.

Gilovich, T. \& Medevec, V. H. (1995). "The Experience of Regret: What, When an Why," Psychological Review, Vol.112, Pp.379-395.

Inman, J.J. \& Zeelenberg, M. (2002). “Regret Repeat Versus Switch Decisions: the Attenuation Role of Decision Justifiability," Journal of Consumer Research, Vol. 29, Pp. 116-128.

Isen, A. M. \& Geva, N. (1987). "The Influence of Positive Affect on Acceptable Level of Risk: the Person with a Large Canoe Has a Large Worry," Organization Behavior and Human Decision Processes, Vol. 39, Pp. 145-154.

Josephs, R. A., Larrick, R. P., Steele, C. M. \& Nisbett, R. E. (1992). "Protecting the Self from the Negative Consequences of Risky Decisions," Journal of Personality and Social Psychology, Vol.62, (January), Pp. 26-37.

Kahneman, D. (1995). Varieties of Counterfactual Thinking in Roese, N. J., Olson, J. M., (Eds), What Might Have Been: the Social Psychology of Counterfactual Thinking, Hillsdale, NJ: Erlbaum.

Kahneman, D. \& Tversky, A. (1982). "The Psychology of Preferences," Scientific American, Vol.246, Pp.160-173.

Kasimatis, M. \& Wells, G. L. (1995). Individual Differences in Counterfactual Thinking, in Roese, N.J., Olson, J.M., (Eds): What Might Have Been :
The Social Psychology Of Counterfactual Thinking, Hillsdale, NJ : Erlbaum.

Landman, J. (1987). "Regret: a Theoretical and Conceptual Analysis," Journal of Theory of Social Behavior, Vol. 17, Pp. 135-160.

Landman J. (1993). "Regret: the Persistence of the Possible," New York: Oxford University Press.

Lee, S. H. \& Cotte, J. (2009). "Post-Purchase Consumer Regret: Conceptualization and Development of the PPCR Scale," Advances in Consumer Research, Vol. 36, Pp. 456- 462.

Markman, K. D., Gavanski, I., Sherman, S. J. \& Mcmullen, M. N. (1993). "The Mental Simulation of Better and Worse Possible Worlds," Journal of Experimental Social Psychology, Vol. 29, Pp. 87-109.

McConnel, A. R., Niedermeier, K. E., Leibold, J. M., El- Alyali, A. G., Chin, P. P. \& Kuiper, N. M. (2000). "What If I Find it Cheaper Someplace Else?: Role of Prefactual Thinking and Anticipated Regret in Consumer Behavior," Psychology and Marketing, Vol.17, Pp. 281- 298.

Mellers, B. A., Schwartz, A. \& Ritov, I. (1999). "Emotion- Based Choice," Journal of Experimental Psychology, Vol. 128, (September), Pp. 332-345.

Meyers-Levy, J. \& Maheswaran, D. (1992). "When Timing Matters: the Influence of Temporal Distance on Consumers' Affective and Persuasive Responses," Journal of Consumer Research, Vol. 19, Pp. 424-433.

Nenkov, G. Y., Morrin, M., Schwartz, B., Ward, A. \& Hulland, J. (2008). "A Short Form of the Maximization Scale: Factor Structure, Reliability, and Validity Studies," Judgment and Decision Making, Vol. 3, Pp. 371-388.

Roese, N. J. \& Olson, J. M. (1993). "SelfEsteem and Counterfactual Thinking," Journal of Personality and Social Psychology, Vol. 65, Pp. 199-206.

Sanna, L. J. (1996). “Defensive Pessimism, Optimism and Simulating Alternatives: Some Ups and Downs of Prefactual and 
Counterfactual Thinking," Journal of Personality and Social Psychology, Vol. 71, Pp. 1020-1036.

Sanna, L. J. (1998). “Defensive Pessimism and Optimism: the Bitter- Sweet Influence of Mood on Performance and Prefactual and Counterfactual Thinking," Cognition and Emotion, Vol. 12, Pp 635-665.

Schwartz, B. (2000). "Self-Determination: the Tyranny of Frdom," American Psychologist, Vol.55, Pp. 79-88.

Schwartz, B., Ward, A., Monterosso, J., Lyubomirsky, S., White, K. \& Lehman, D. R. (2002). "Maximiszing Versus Satisficing: Happiness in a Matter of Choice," Journal of Personality and Social Psychology, Vol. 83, Pp. 1178- 1197.

Simonson, I. (1992). "The Influence of Anticipating Regret and Responsibility on Purchase Decisions," Journal of Consumer Research, Vol.19, №.1, Pp. 105-118.

Sugden, R. (1985). "Regret, Recrimination and Rationality," Theory and Decision, Vol. 19, Pp. 77-99.

Tsiros, M. \& Mittal, V. (2000). "Regret: a Model of its Antecedents and Consequences in Consumer Decision Making," Journal of Consumer Research, Vol. 26, Pp.401-417.

Van Dijk, W. W., Van Der Pligt, J. \& Zeelenberg, M. (1999). "Effort Invested in Vain: the Impact of Effort on the Intensity of Disappointment and Regret," Motivation and Emotion, Vol.23, (September).

Yi, Y. (1990). "A Critical Review of Consumer Satisfaction," Review of Marketing, Ed. V.A. Zeithaml, Chicago, American Marketing Association.

Zeelenberg, M., Beattie, J., Van Der Pligt, J. \& De Vries, N. K. (1996). "Consequences of Regret Aversion: Effects of Expected Feedback on Risky Decision Making," Organizational Behavior and Human Decision Process, Vol. 65, (February), Pp. 148-158.

Zeelenberg, M. \& Pieters, R., (2004). "Beyond Valence in Customer
Dissatisfaction : a Review and New Findings on Behavioral Responses to Regret and Disappointment in Filed Services," Journal of Business Research, Vol. 57, Pp. 445-455.

Zeelenberg, M. \& Pieters, R. (2006). "Looking Backward with an Eye on the Future : Propositions Toward a Theory of Regret Regulation," in Judgments Over Time: the Interplay of Thoughts, Feeling and Behavior, Eds. L. J., Sanna and E. C., Chang, New York, NY: Oxford University Press, Pp. 210-229.

Zeelenberg, M. \& Pieters, R. (2007). "A Theory of Regret Regulation 1.0," Journal of Consumer Psychology, Vol.17, Pp.3-18.

Zeelenberg, M., Van Dijk, W. W. \& Manstead, A. S. R. (2000). "Regret and Responsibility Resolved? Evaluating Ordonez and Connolly's (2000) Conclusions," Organizational Behavior and Human Decision Processes, Vol.81, Pp.143154.

Zeelenberg, R., Wagenmakers, E.- J. \& Shiffrin, R. M. (2004). "Nonword Repetition Priming in Lexical Decision Reverses as a Function of Study Task and Speed Stress," Journal of Experimental Psychology: Learning, Memory, and Cognition, Vol.30, Pp.270 -277. 